\title{
Downstream effects of polypathology on neurodegeneration of medial temporal lobe subregions
}

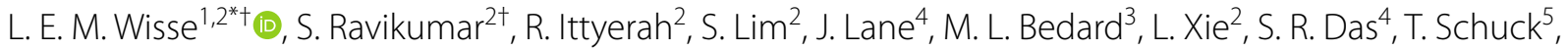

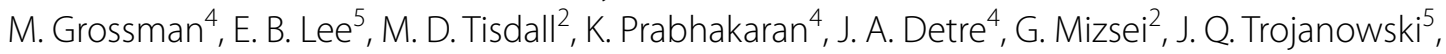 \\ E. Artacho-Pérula ${ }^{6}$, M. M. de Iñiguez de Onzono Martin', M. M. Arroyo-Jiménez ${ }^{6}$, M. Muñoz Lopez \\ F. J. Molina Romero ${ }^{6}$, M. P. Marcos Rabal ${ }^{6}$, S. Cebada Sánchez ${ }^{6}$, J. C. Delgado González ${ }^{6}$, C. de la Rosa Prieto ${ }^{6}$, \\ M. Córcoles Parada ${ }^{6}$, D. A. Wolk ${ }^{4}$, D. J. Irwin ${ }^{4,5}$, R. Insausti ${ }^{6}$ and P. A. Yushkevich ${ }^{2}$
}

\begin{abstract}
The medial temporal lobe (MTL) is a nidus for neurodegenerative pathologies and therefore an important region in which to study polypathology. We investigated associations between neurodegenerative pathologies and the thickness of different MTL subregions measured using high-resolution post-mortem MRI. Tau, TAR DNA-binding protein 43 (TDP-43), amyloid- $\beta$ and $\alpha$-synuclein pathology were rated on a scale of 0 (absent) - 3 (severe) in the hippocampus and entorhinal cortex (ERC) of 58 individuals with and without neurodegenerative diseases (median age 75.0 years, 60.3\% male). Thickness measurements in ERC, Brodmann Area (BA) 35 and 36, parahippocampal cortex, subiculum, cornu ammonis (CA) 1 and the stratum radiatum lacunosum moleculare (SRLM) were derived from $0.2 \times 0.2 \times 0.2$ $\mathrm{mm}^{3}$ post-mortem MRI scans of excised MTL specimens from the contralateral hemisphere using a semi-automated approach. Spearman's rank correlations were performed between neurodegenerative pathologies and thickness, correcting for age, sex and hemisphere, including all four proteinopathies in the model. We found significant associations of (1) TDP-43 with thickness in all subregions ( $r=-0.27$ to $r=-0.46)$, and (2) tau with BA35 $(r=-0.31)$ and SRLM thickness ( $r=-0.33$ ). In amyloid- $\beta$ and TDP-43 negative cases, we found strong significant associations of tau with ERC ( $r=-0.40)$, BA35 ( $r=-0.55)$, subiculum $(r=-0.42)$ and CA1 thickness $(r=-0.47)$. This unique dataset shows widespread MTL atrophy in relation to TDP-43 pathology and atrophy in regions affected early in Braak stageing and tau pathology. Moreover, the strong association of tau with thickness in early Braak regions in the absence of amyloid- $\beta$ suggests a role of Primary Age-Related Tauopathy in neurodegeneration.
\end{abstract}

\section{Introduction}

It has become increasingly evident that multiple neurodegenerative pathologies often co-occur in the brains of older adults and contribute to cognitive decline [31,

\footnotetext{
*Correspondence: lemwisse@gmail.com

${ }^{\dagger}$ L.E.M. Wisse and S. Ravikumar have contributed equally to this work

1 Department of Diagnostic Radiology, Lund University, Klinikgatan 13b, Lund, Sweden

Full list of author information is available at the end of the article
}

$41,55,56]$. In the presence of neurodegenerative disorders, such as pathologically confirmed Alzheimer's disease (AD), other pathologies such as $\alpha$-synuclein and TAR DNA-binding protein 43 (TDP-43) co-occur frequently $[31,55,56]$. These common neurodegenerative pathologies show a characteristic pattern of progression throughout the brain, where the medial temporal lobe (MTL) is frequently an early nidus $[5,7,27,46,59]$, making the MTL an important region in which to study polypathology. For example, neurofibrillary tangle (NFT)

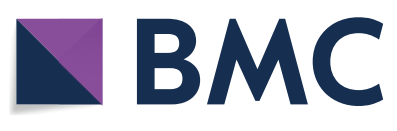

(c) The Author(s) 2021. Open Access This article is licensed under a Creative Commons Attribution 4.0 International License, which permits use, sharing, adaptation, distribution and reproduction in any medium or format, as long as you give appropriate credit to the original author(s) and the source, provide a link to the Creative Commons licence, and indicate if changes were made. The images or other third party material in this article are included in the article's Creative Commons licence, unless indicated otherwise in a credit line to the material. If material is not included in the article's Creative Commons licence and your intended use is not permitted by statutory regulation or exceeds the permitted use, you will need to obtain permission directly from the copyright holder. To view a copy of this licence, visit http://creativecommons.org/licenses/by/4.0/. The Creative Commons Public Domain Dedication waiver (http://creativeco mmons.org/publicdomain/zero/1.0/) applies to the data made available in this article, unless otherwise stated in a credit line to the data. 
pathology, a hallmark of $\mathrm{AD}$, first accumulates in the transentorhinal region (which approximates Brodmann Area (BA) 35) and the lateral part of the entorhinal cortex (ERC), before spreading to the cornu ammonis 1 (CA1) subfield of the hippocampus, according to Brak and Braak [5].

In recent years, studies with both antemortem MRI and autopsy data have started to shed light on how different neurodegenerative pathologies are associated with different atrophy patterns in the brain and the MTL specifically $[3,15,28,29,40,46,52,66]$. These studies enable the identification of patterns of neurodegeneration specific to each of the neurodegenerative pathologies. Since the field currently lacks reliable molecular in vivo biomarkers for TDP-43 or $\alpha$-synuclein pathologies, incorporating proteinopathy-specific patterns of brain atrophy into structural MRI biomarkers offer a promising opportunity for detecting and monitoring these pathologies in vivo. Such patterns could also provide early AD imaging biomarkers for neurodegeneration that are more specific to Alzheimer's Disease Neuropathological Change (ADNC) and less confounded by comorbid pathologies than current commonly used MRI biomarkers of neurodegeneration (e.g. whole hippocampal atrophy).

While previous studies combining antemortem MRI and neuropathology data are very valuable, they are hampered by relatively low image resolution precluding more granular measures of the MTL. Moreover, there is often a long time interval (often 1 year or greater) between the MRI and autopsy that can weaken the association between in vivo measures of neurodegeneration and the underlying neurodegenerative pathologies. In this study, we aimed to advance upon previous work by investigating the association between semi-quantitative measures of four primary neurodegenerative pathologies (i.e. amyloid- $\beta$ plaques, tau, $\alpha$-synuclein and TDP-43) and the thickness of different MTL subregions measured on ultra high resolution postmortem MRI in a large dataset of brain donors with a broad range of neurodegenerative diagnoses but also some without any neurodegenerative disease. As part of this analysis, we also study the association of tau pathology with MTL subregional thickness in the absence of amyloid- $\beta$ plaques to interrogate Primary Age-related Tauopathy, or PART [10].

We hypothesize that tau pathology score will be associated with BA35, ERC and CA1 thickness both in the presence and absence of amyloid- $\beta$ [5], but also in the stratum radiatum lacunosum moleculare (SRLM) of CA because this layer is an early target of neurofibrillary pathology [4]. We hypothesize that TDP-43 pathology score will be associated with ERC and subiculum thickness [47]. We do not expect strong associations with MTL thickness measures for amyloid- $\beta$ plaques $[18,19$,
$21]$ and $\alpha$-synuclein pathology $[8,9,14,15]$ based on previous literature. However, with our ultra high resolution images and subregional measurements, we might be able to pick up more subtle effects on MTL subregions.

\section{Methods \\ Specimens and postmortem MRI}

Brain hemispheres were obtained from 58 donors; 45 specimens from autopsies performed at the University of Pennsylvania Center for Neurodegenerative Disease Research (CNDR) and 13 specimens from the University of Castilla-La Mancha Human Neuroanatomy Laboratory (HNL). Human brain specimens were obtained in accordance with the University of Pennsylvania Institutional Review Board guidelines. Where possible, pre-consent during life and, in all cases, next-of-kin consent at death was given. CNDR hemispheres were fixed in $10 \%$ formalin solution for at least 30 days before extracting intact MTL blocks. HNL cases were fixed by perfusion with $4 \%$ paraformaldehyde through both carotid arteries. The blocks were then imaged on 9.4 tesla small-bore scanner (Varian, Palo Alto, CA) at $0.2 \times 0.2 \times 0.2 \mathrm{~mm}^{3}$ resolution [1]. Details of the imaging protocol are provided in the Supplementary Material.

For this study, we were unable to obtain MRI measures and clinical neuropathology scores in the same hemisphere for each specimen. Therefore, for all specimens imaging was done on the hemisphere contralateral to the neuropathological assessment. For CNDR, cases came from the Frontotemporal Dementia Center (FTDC) and the Alzheimer's Disease Research Center (ADRC). For the cases from the FTDC, the less affected hemisphere was typically selected for imaging because of ongoing studies at CNDR that require the most affected hemisphere. For cases in which antemortem T2-weighted in vivo MRI was available, the hemisphere with the best in vivo scan quality was selected for imaging. For the remaining cases the hemisphere for imaging was selected at random.

\section{MTL thickness measurements}

Measurements were performed in the ERC, BA35, BA36 (BA35 and BA36 together make up the perirhinal cortex), parahippocampal cortex (PHC), subiculum (SUB), CA1 and SRLM. We selected MTL regions that we could identify on postmortem MRI with sufficient certainty. While CA2 or CA3 would also have been interesting, these regions are difficult to identify on MRI and were therefore not included. We included the SRLM because this layer of CA can be identified on high resolution MRI and is an early target of neurofibrillary pathology [4] and has been shown to be thinner in clinical AD [1,32]. Our SRLM label refers to the thin hypointense structure 
(also known as the "dark band" [16]) that can be identified reliably on T2-weighted MRI, which mainly reflects the strata lacunosum and moleculare and not the stratum radiatum (see Figure 6 in [16]).

For each subregion, two separate locations along the anterior-posterior axis of the MTL were identified to obtain thickness measurements, see Additional file 1: Fig. 1 and Supplementary Methods for more details. For each anatomical location (marked with a dot), cortical thickness was measured by using semi-automated active contour segmentation in ITK-SNAP [67] (with possible manual correction) to segment a portion of the surrounding gray matter extending $\sim 5-10 \mathrm{~mm}$ from the dot in all directions (see Fig. 1). Thickness at each location was measured as the diameter of the sphere overlapping the dot, fully contained in the gray matter segmentation

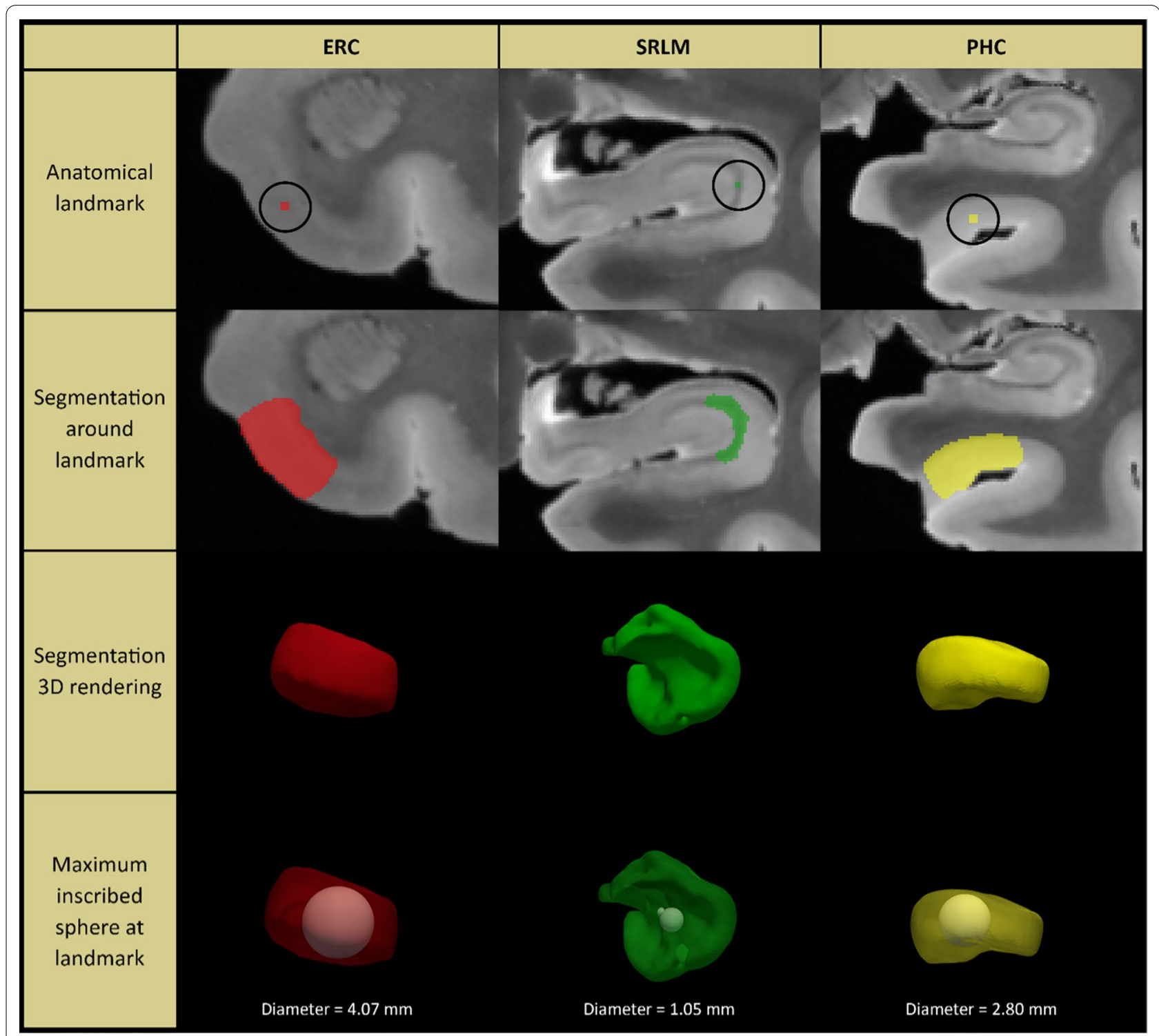

Fig. 1 Method for obtaining thickness measures from high-resolution post-mortem MRI in medial temporal lobe subregions. For each anatomical location (indicated by a dot; first row), cortical thickness was measured by using semi-automated active contour segmentation in ITK-SNAP (with possible manual correction) to segment a portion of the surrounding gray matter extending $\sim-10 \mathrm{~mm}$ from the dot in all directions (second and third row). Thickness at each location was measured as the diameter of the sphere overlapping the dot, fully contained in the gray matter segmentation, and having maximum possible radius (fourth row). Segmentations and fitted spheres were visually inspected for quality assurance. See supplementary Methods for details. Note that we only show three examples in this figure. For this study we performed thickness measurements for seven subregions and averaged thickness measurements over two locations for each subregion, see Additional file 1: Fig. 1. ERC = entorhinal cortex; $\mathrm{SRLM}=$ stratum radiatum lacunosum moleculare; $\mathrm{PHC}=$ parahippocampal cortex 
and with the maximum possible radius. Segmentations and fitted spheres were visually inspected for quality assurance. Thickness measures were then averaged over the two locations to obtain a single thickness measure per subregion. Thickness measurements could not always be performed for each location in each specimen, due to tears, other tissue damage or lack of contrast. We therefore reported the sample size for each subregion in the tables.

Note that we performed the thickness measurements in raw reconstructed MRI scans, in contrast to our previous paper [1], which is further explained in the Supplementary Material.

\section{Neuropathology measures}

Analysis of the neuropathological data was performed at the University of Pennsylvania. Neuropathological assessments were performed by expert neuropathologists using established neuropathologic criteria for AD and related disorders [24, 39, 42, 45] using standard ordinal ratings scores. Neuropathology scoring has been established to be highly reliable between raters within and between laboratories [44]. Thirteen regions are routinely examined in the CNDR neuropathology evaluations as described in previous publications [60]. More precisely, tissue was embedded in paraffin blocks and cut into $6 \mu \mathrm{m}$ sections for immunohistochemistry using the well-characterized primary antibodies and established methods (see [60] for more info): NAB228 (monoclonal antibody [mAb], 1:8000, generated in the CNDR) to detect amyloid- $\beta$ deposits, phosphorylated tau PHF-1 (mAb, 1:1000, a gift from Dr. Peter Davies) to detect phosphorylated tau deposits, TAR5P-1D3 (mAb, 1:500, a gift from Dr. Manuela Neumann and Dr. E. Kremmer) to detect phosphorylated TDP-43 deposits and Syn303 (mAb, 1:16,000, generated in the CNDR) to detect the presence of pathological conformation of $\alpha$-synuclein. The epitope specificity has been previously published in detail for the monoclonal antibodies used in this study. We use NAB228 that recognizes a N-terminal A $\beta$ epitope that detects diffuse and neuritic plaque pathology [35], PHF-1 for tau phosphorylated at serine 396 and 404 [50], SYN303 for a disease specific conformation of alpha-synuclein [20] and ID3 for TDP-43 phosphorylated at residues 409/410 [48]. Each region was assigned a semiquantitative score i.e. none $(0)$, rare $(0.5)$, mild (1), moderate (2) or severe (3) for individual lesions (tau, amyloid- $\beta$, TDP-43 and $\alpha$-synuclein pathologies). Note that the tau pathology score in this dataset represents multiple conformations of tau; it includes not only the $3 R / 4 R$ tau typically associated with NFT, but also 3R and $4 R$ tau associated with non-AD tauopathies. Assessment of pathology scoring has been well-established.
For example, plaque scores are based on CERAD (Consortium to Establish a Registry for Alzheimer's Disease) criteria [43]. Tau scores are based on the Braak staging scheme which describes not only the distribution but the severity of tauopathy across AD stages [6]. Scores for $\alpha$-synuclein pathology are based on the McKeith criteria [42]. TDP-43 scoring was performed using criteria outlined by Mackenzie et al. [38]. All scores are established by examining sections at multiple levels of magnification to ensure adequate sampling of different regions of the section (at lower power) and ensuring accuracy (at higher power). An example of mild and severe pathology for each of the pathologies can be found in Additional file 1: Fig. 2. In an effort to preserve the scanned specimens for serial histopathology, these ratings were done by sampling the contralateral hemisphere. A composite score for the MTL was calculated by averaging the scores of CA1/ SUB, ERC and dentate gyrus for each lesion of interest (tau, amyloid- $\beta$, TDP-43 and $\alpha$-synuclein).

\section{Statistical analyses}

Partial Spearman correlation analyses were performed with $\mathrm{R}$ package ppcor. Covariates included in the model were age, sex and hemisphere. Note that because of the relatively small size of this unique dataset, we did not correct for multiple comparisons.

\section{Results \\ Demographics}

Table 1 shows the demographics of the brain donor cohort and the subset who were considered amyloid- $\beta$ negative (A-; defined by an A-score of 0 or 1 ). In brief, these 58 individuals had a median age of 75.0 years (range: 44-97) and 60.3\% were male. Among the $35 \mathrm{~A}$ donors, the average age was 73.0 years (range: 44-93) and $57.1 \%$ were male. Both the full cohort and the A- subcohort showed a wide range of neuropathological diagnoses. The MTL neuropathology scores as well as global neuropathological staging scores for AD neuropathological change (i.e. A, B and C scores [23]) are also reported in Table 1.

\section{Association of neurodegenerative pathologies with MTL subregional thickness measures}

Full dataset Spearman partial correlations, corrected for age, sex and hemisphere, revealed a significant association between MTL tau pathology score and cortical thickness in regions affected early in Braak stageing, namely BA35, SRLM of the hippocampus, and at a trend level for ERC (Table 2). Note that the MTL tau pathology score in this dataset represents total burden of tau inclusions, 
Table 1 Participant demographics

\begin{tabular}{|c|c|c|}
\hline & Full dataset & A-subset \\
\hline Number of specimens & 58 & 35 \\
\hline Sex (\% male) & 60.3 & 57.1 \\
\hline Age (years) Median (range) & 75.0 (44-97) years & 73.0 (44-93) years \\
\hline Mean $\pm S D$ & $74.7 \pm 11.3$ years & $72.0 \pm 10.7$ years \\
\hline \multicolumn{3}{|l|}{ MTL Tau score } \\
\hline Mean $\pm S D$ (range) & $1.64 \pm 0.93(0-3)$ & $1.34 \pm 0.96(0-3)$ \\
\hline$\%$ score $>0(\mathrm{~N})$ & $96.6 \%(56)$ & $94.3 \%(33)$ \\
\hline \multicolumn{3}{|l|}{ MTL TDP-43 score } \\
\hline Mean \pm SD (range) & $0.47 \pm 0.91(0-3)$ & $0.52 \pm 0.99(0-3)$ \\
\hline$\%$ score > $0(\mathrm{~N})$ & $27.6 \%(16)$ & $25.7 \%(9)$ \\
\hline \multicolumn{3}{|l|}{ MTL amyloid- $\beta$ scores } \\
\hline Mean \pm SD (range) & $0.92 \pm 0.99(0-3)$ & $0.31 \pm 0.59(0-3)$ \\
\hline$\%$ score > $0(\mathrm{~N})$ & $63.8 \%(37)$ & $40.0 \%(14)$ \\
\hline \multicolumn{3}{|l|}{ MTL a-synuclein score } \\
\hline Mean \pm SD (range) & $0.21 \pm 0.54(0-2.33)$ & $0.08 \pm 0.30(0-1.67)$ \\
\hline$\%$ score > $0(\mathrm{~N})$ & $17.2 \%(10)$ & $8.6 \%(3)$ \\
\hline \multicolumn{3}{|l|}{ Primary neuropathological diagnosis } \\
\hline None/limited pathology ${ }^{\mathrm{a}}$ & $20.7 \%(8)$ & $31.4 \%(7)$ \\
\hline Intermediate-high ADNC & $25.9 \%(15)$ & $0 \%(0)$ \\
\hline $\mathrm{CBD}$ & $5.2 \%(3)$ & $8.6 \%(3)$ \\
\hline FTLD-TDP & $13.8 \%(8)$ & $20.0 \%(7)$ \\
\hline LBD & $8.6 \%(5)$ & $2.9 \%(1)$ \\
\hline Other $^{b}$ & $13.8 \%(7)$ & $17.1 \%(6)$ \\
\hline PART & $8.6 \%(5)$ & $14.3 \%(5)$ \\
\hline Pick's disease & $5.2 \%(3)$ & $8.6 \%(3)$ \\
\hline PSP & $6.9 \%(4)$ & $8.6 \%(3)$ \\
\hline Two or more neuropathological diagnoses & $70.7 \%(41)$ & $65.7 \%(23)$ \\
\hline \multicolumn{3}{|l|}{ Ascore } \\
\hline 0 & $25.9 \%(15)$ & $42.9 \%(15)$ \\
\hline 1 & $34.5 \%(20)$ & $57.1 \%(20)$ \\
\hline 2 & $8.6 \%(5)$ & $0.0 \%(0)$ \\
\hline 3 & $31.0 \%(18)$ & $0.0 \%(0)$ \\
\hline \multicolumn{3}{|l|}{ Bscore } \\
\hline 0 & $22.4 \%(13)$ & $37.1 \%(13)$ \\
\hline 1 & $29.0 \%(18)$ & $42.9 \%(15)$ \\
\hline 2 & $20.0 \%(11)$ & $14.3 \%(5)$ \\
\hline 3 & $21.0 \%(13)$ & $0.0 \%(0)$ \\
\hline Missing & $11.3 \%(3)^{b}$ & $5.7 \%(2)^{b}$ \\
\hline \multicolumn{3}{|l|}{ Cscore } \\
\hline 0 & $55 . \%(32)$ & $82.9(29)$ \\
\hline 1 & $17.2 \%(10)$ & $17.1 \%(6)$ \\
\hline 2 & $3.4 \%(2)$ & $0.0 \%(0)$ \\
\hline 3 & $24.1 \%(14)$ & $0.0 \%(0)$ \\
\hline
\end{tabular}

The MTL pathology scores shown in the table are the averages of the semi-quantitative ratings in the entorhinal cortex, cornu ammonis 1 and dentate gyrus from the hemisphere contralateral to the MRI scan

MTL medial temporal lobe, TDPTAR DNA-binding protein, ADNC Alzheimer's disease neuropathological change, CBD corticobasal degeneration, FTLD frontotemporal lobar degeneration, $L B D$ Lewy body disease, PART primary age-related tauopathy, PSP progressive supranuclear palsy. ${ }^{\mathrm{a}} \mathrm{Also}$ includes patients with low ADNC. ${ }^{\mathrm{B}} \mathrm{B}$ score

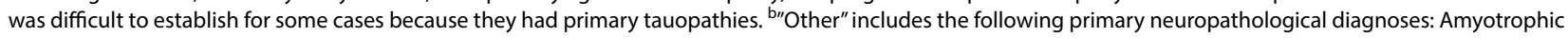
Lateral Sclerosis $(n=1)$; Argyrophylic Grain Disease $(n=2)$; cerebrovascular disease $(n=1)$; multiple system atrophy $(n=1)$; other $(n=1)$; tauopathy unclassifiable $(n=1)$ 
Table 2 Partial Spearman correlations of semiquantitative MTL scores of neurodegenerative pathologies with MTL subregional thickness measures, including all pathologies in the same model

\begin{tabular}{lccccccc}
\hline & ERC & BA35 & BA36 & PHC & SUB & CA1 & SRLM \\
\hline Sample size & 55 & 53 & 53 & 56 & 58 & 58 & 57 \\
Amyloid- $\beta$ & 0.10 & 0.11 & -0.02 & -0.18 & 0.05 & 0.05 & -16 \\
Tau & $-0.26^{\text {a }}$ & $-\mathbf{0 . 3 1 ^ { * }}$ & 0.08 & 0.06 & -0.13 & -0.16 & $-\mathbf{0 . 3 3 ^ { * }}$ \\
TDP-43 & $-\mathbf{0 . 4 4 ^ { * * }}$ & $-\mathbf{0 . 4 6 ^ { * * }}$ & $-\mathbf{0 . 3 5 ^ { * }}$ & $-\mathbf{0 . 4 5 * * *}$ & $-0.27^{\text {a }}$ & $-\mathbf{0 . 3 9 ^ { * * }}$ & $-\mathbf{0 . 4 6 ^ { * * * }}$ \\
a-synuclein & 0.01 & -0.01 & 0.02 & 0.12 & 0.16 & 0.17 & -0.12 \\
\hline
\end{tabular}

All models are corrected for age, sex and hemisphere

${ }^{a} p<0.10 ;{ }^{*} p<0.05 ;{ }^{* *} p<0.01 ; * * * 0<0.001$. Significant results are bolded. TDPTAR DNA-binding protein, ERC entorhinal cortex, BA Brodmann area, PHC parahippocampal cortex, SUB subiculum, CA cornu ammonis, SRLM stratum radiatum lacunosum moleculare

including multiple conformations of tau. Widespread significant associations were also observed between MTL TDP-43 pathology score and all MTL subregional thickness measures. No significant associations with thickness were observed for amyloid- $\beta$ or $\alpha$-synuclein pathologies. Scatterplots of the pathology/thickness associations are shown in Additional file 1: Figs. 3-4.

Supplementary analyses in the full dataset To investigate if tau and TDP-43 have a synergistic effect on neurodegeneration, we performed the analyses with an interaction term for MTL tau and TDP-43 scores. However, the interaction term was not significant for any region.

Since previous studies have shown that TDP-43 associations demonstrate an anterior-to-posterior gradient [22, 47], the analyses were repeated separately for anterior and posterior hippocampal subfield thickness measures, however no clear pattern arose (see Additional file 1: Table 1).

Third, to explore if there was a sex difference in the association of pathology ratings with thickness measures, we repeated all analyses that showed a significant association between pathology and thickness measure (see Table 2) including an interaction term with sex"pathology, but separately for tau and TDP-43 pathology. None of the interaction terms reached significance, except for tau*sex on BA35 $(p=0.006)$. Repeating the analyses separately for each sex showed that the association of tau pathology with BA35 thickness was stronger in females (correlation $=-0.62 ; p=0.003$ ) than males (correlation $=-0.11 ; p=0.59$ ), see Additional file 1 : Fig. 5. Note that no significant differences were observed between males and females in BA35 thickness (females: $2.87 \pm 0.63$; males: $2.79 \pm 0.43$ ) or MTL tau ratings (females: $1.50 \pm 0.88$; males: $1.74 \pm 0.96$ ).

Fourth, to explore the effect of neuropathological diagnoses on the observed thickness-pathology analyses, Additional file 1: Figs. 6 and 7 illustrate the potential effect of diagnosis in different scatterplots. BA35 thickness is selected for these figures as an example, as the associations for tau and TDP-43 pathology were both strong for this specific subregion. The figures show different versions of the scatterplots for BA35 in Additional file 1: Figs. 3 and 4, each version highlighting cases that have one of the eight main neuropathological diagnoses, regardless of whether it was listed as a primary, secondary or tertiary neuropathological diagnosis. As can be seen in the figures, the different diagnoses do not seem to drive the observed association between BA35 thickness and either tau or TDP-43 pathology, except for frontotemporal lobar degeneration with TDP-43 inclusions (FTLD-TDP) which, as expected, partly seems to drive the association between TDP-43 and BA35 thickness.

Amyloid- $\beta$ negative subset Table 3 shows that in A- subjects, MTL tau score was significantly associated with BA35 and at a trend level with ERC and CA1. In Additional file 1: Fig. 8 it can be observed that the association of MTL tau score with MTL structural measures may be obscured by individuals who have a low tau but high TDP-43 score. We therefore repeated the analyses in cases with low or absent levels of TDP-43 based on the MTL score in the hippocampus/ERC. The cut off was defined as $<0.5$, based on inspection of the data where most subjects had a score of 0 or 0.17 and all other subjects had a score of 0.67 or higher. Significant associations were observed between MTL tau score and thickness of BA35, ERC, SUB and CA1 and at a trend level with SRLM. Scatterplots are shown in Additional file 1: Fig. 9.

\section{Discussion}

This unique dataset combining measures of multiple neurodegenerative pathologies with ultra-high resolution post-mortem MRI in a large dataset of 58 brain specimens allowed us to investigate the association of frequently comorbid neurodegenerative pathologies with granular structural measures of the MTL, a 
Table 3 Partial Spearman correlations of semiquantitative MTL scores of neurodegenerative pathologies with MTL subregional thickness measures in different subgroups, including only tau in the model

\begin{tabular}{llllllll}
\hline & ERC & BA35 & BA36 & PHC & SUB & CA1 & SRLM \\
\hline Sample size & 55 & 53 & 53 & 56 & 58 & 58 & 57 \\
Tau in full dataset & $-0.27^{\text {a }}$ & $-\mathbf{0 . 3 0 ^ { * }}$ & 0.04 & -0.06 & -0.13 & -0.18 & $-\mathbf{0 . 3 1 ^ { * }}$ \\
Sample size & 33 & 31 & 32 & 34 & 35 & 35 & 34 \\
Tau in A-subset & $-0.31^{\text {a }}$ & $-\mathbf{0 . 3 7 ^ { * }}$ & -0.06 & 0.14 & -0.22 & $-0.30^{\text {a }}$ & -0.15 \\
Sample size & 25 & 23 & 24 & 26 & 27 & 27 & 26 \\
Tau in A-TDP-subset & $-\mathbf{0 . 4 5 ^ { * }}$ & $\mathbf{- 0 . 5 2 ^ { * }}$ & -0.08 & -0.09 & $\mathbf{- 0 . 4 4 ^ { * }}$ & $-\mathbf{0 . 4 5}^{*}$ & $-0.38^{\text {a }}$ \\
\hline
\end{tabular}

All models are corrected for age, sex and hemisphere

${ }^{a} p<0.10 ;{ }^{*} p<0.05 ;{ }^{* *} p<0.01 ;{ }^{* * *} p<0.001$. Significant results are bolded. ERC entorhinal cortex, BA Brodmann area, $P H C$ parahippocampal cortex, SUB subiculum, CA cornu ammonis, SRLM stratum radiatum lacunosum moleculare

hotspot for several neurodegenerative pathologies. We found widespread associations of MTL TDP-43 score with almost all MTL subregional thickness measures, whereas MTL tau score showed a more circumscribed pattern involving regions affected early in Braak stageing. In the absence of amyloid- $\beta$ pathology, again strong associations of tau pathology were found with structural measures of regions affected early in Braak stageing.

Our results showing widespread MTL atrophy related to MTL TDP-43 score agree with two previous studies using antemortem MRI $[3,15]$. This result is also in line with previous studies investigating specifically either the hippocampus or the amygdala $[8,30,40,58,66]$. There was one study by Wennberg et al. that did not report an association between TDP-43 and MTL structural measures [64], potentially because the participants in this study were clinically normal. No specific anterior-to-posterior gradient of atrophy in relation to TDP-43 was found in our study, which contrasts with the recent antemortem MRI study in an overlapping cohort of individuals [15]. This may be due to our cases being in more advanced stages of the disease or due to a difference in the selection of study subjects. The De Flores et al. study only included patients with intermediate to high ADNC [15], whereas our study included subjects with any neurodegenerative disease and likely had a higher percentage of subjects with FTLD-TDP. Notably TDP-43 pathology has been found to be associated with MTL atrophy both in the presence and absence of FTLD-TDP [3, 28, 40].

As previous studies have mostly analyzed gross MTL measures such as total hippocampal volume, the current study expands our knowledge by providing analyses of more granular MTL subregional measures. While TDP-43 pathology did not demonstrate associations with any specific MTL subregion, our dataset is growing and more quantitative measures for TDP-43 pathology are being generated [68] which in the future will allow for more fine-grained analyses or analyses in subgroups such as the recently introduced Limbic Agerelated TDP-43 Encephalopathy, or LATE [46].

The atrophy pattern associated with tau pathology was more specifically restricted to regions affected early in Braak stageing: BA35, ERC (trend) and SRLM. Braak et al. identified BA35 (referred to as transentorhinal region in their report) and the lateral aspect of ERC as the earliest cortical site of tau NFT pathology [5]. Relatively early impact of NFT pathology in SRLM of CA, a region consisting of the apical dendrites [17], has also been reported [6]. Moreover, NFT pathology has long been associated with neuron loss in BA35 and ERC and neuropil loss in SRLM in multiple ex vivo studies $[1,18,21,61]$. The current study provides the missing piece in the story of how tau pathology relates to structural MTL measures, complementing studies reporting associations between tau pathology and neuron loss [18, 21, 61], studies reporting associations between tau pathology and gross antemortem MRI measures such as total hippocampal volume [11] and more recently, studies reporting associations between in vivo biomarkers of tau pathology and MTL structural measures $[12,37,62,65]$. This study confirms that the loss of neurons in granular regions in relation to tau pathology can be observed in measures that are more macrostructural than neuron loss, but still fine-grained, such as SRLM, ERC and BA35 thickness. This is a promising finding as these measures can also be obtained from high resolution in vivo MRI and could thus be used to detect early tau related pathology.

Moreover, we found preliminary evidence for a sex difference in the association between tau pathology and the earliest cortical region to be affected by NFT pathology, i.e. BA35, which may indicate that females may be less resilient to the effects of tau pathology. While this is a small sample to study sex differences and this finding is preliminary, it does fit with previous findings of higher 
atrophy rates in females [2] and a higher degree of metabolic dysfunction in the entorhinal cortex in response to tau pathology in females [53], compared to males. Although one previous study showed the opposite, that females showed more preservation of brain structure in the presence of tau [49]. We did not find higher levels of MTL tau pathology in females compared to males in contrast to previous studies [36,51], which may be due to the small sample size in the current study. In general, this study further supports the importance of investigating sex differences in the pathogenesis of $\mathrm{AD}$ and future studies are required to further elucidate this.

We also found strong associations between MTL tau score and thickness in regions affected early in Braak stageing in the absence of amyloid- $\beta$, suggesting a role for PART in driving neurodegeneration. While associations between NFT pathology and volume loss of gross MTL regions measured on MRI have been reported before [29, 52], studies investigating this association have been very sparse. This is an important area of research, as the ramifications of PART are still unclear. In this study we provide further evidence that tau pathology in the absence of amyloid- $\beta$ is not harmless and is in fact associated with structural changes in the MTL. Moreover, it extends previous work by providing a more fine-grained pattern of atrophy within the MTL, beyond total hippocampal volume. Our findings align well with recent in vivo studies showing associations between Tau-PET uptake and MTL structural measures in amyloid- $\beta$ negative subjects $([12,37]$ and provides support for the notion that PART may be underlying at least some Suspected non-Alzheimer's pathophysiology (SNAP) cases [25, 26], a group of subjects who show AD-like neurodegeneration in the absence of amyloid- $\beta$. However, we note two studies where no association between Tau-PET uptake and MTL structural measures were reported in amyloid- $\beta$ negative subjects $[13,63])$.

It should be noted that the A-group in the current study actually includes a large variety of diagnoses (see Table 1) and the MTL tau score used in this study does not only reflect NFT pathology but also other conformations of tau (e.g. FTLD-Tau) [34]. However, the involvement of regions affected early in Braak stageing in our study are less implicated in FTLD-Tau [34], suggesting that age-related NFT pathology and not FTLD-Tau pathology is likely driving the observed associations. Additionally, repeating the analyses after excluding subjects with FTLD-Tau and Argyrophilic grain disease, we observed largely similar results, albeit weaker likely due to the smaller sample size (see Additional file 1: Table 2). Notably, the associations of MTL tau pathology score with MTL subregional thickness measures became stronger after excluding cases with high MTL TDP-43 scores. Indeed, as shown in Additional file 1: Fig. 5, some low tau/high TDP-43 cases may have obscured the associations between tau and structural measures. This finding has important implications for in vivo studies, for example, those investigating the associations between structural MRI and tau PET uptake or phosphorylated tau measured in cerebrospinal fluid, especially when these studies include the higher age range at which TDP43 pathology is common [47].

The strengths of this study are the large sample size, the analysis of multiple pathologies and the granular assessment of $0.2 \times 0.2 \times 0.2 \mathrm{~mm}^{3}$ postmortem MRI. This study also has some limitations. The first limitation is the different fixation methods used at the CNDR and HNL (see section "Specimens and Postmortem MRI"). While fixation method may be a potential confounder in the thickness analyses, we could not correct for this in our analyses as fixation method is confounded by diagnosis, i.e. all non-neurological specimens are processed with a different fixation method than those with a dementia diagnosis. However, as all results regarding the associations of TDP-43 pathology and tau pathology are in line with the literature and as all brain specimens, regardless of fixation method, were fully fixed, we do not expect that this played an important role. Another limitation is that we did not correct for multiple comparisons because of the uniqueness of the data and the sample size. While this increases the chance of false positives, we believe that this issue was limited in this paper as our findings matched previous literature. A source of variability in postmortem studies assessing structural measures is brain swelling. We noticed one subject with severe brain swelling (when compared to the antemortem MRI, which was available in this subject). We reran the analyses without this subject but saw no notable differences in the results (see Additional file 1: Tables 3 and 4). A last limitation is that neuropathological scores were established in the contralateral hemisphere. While having neuropathological scores and thickness measurements in the same hemisphere would have been preferable, this data is not available in the current study as the imaged hemispheres are still undergoing additional processing, including dense sectioning which is a very labor intensive process. Moreover, this additional processing, as part of a larger study, includes different sectioning and staining methods in which we are less confident about the pathology score compared to what is typically done in the CNDR and other neuropathology centers. While inter-hemispheric differences have been observed for neurodegenerative pathologies, these do not seem to be systematic $[33,57]$ and we there do not expect this to have affected our results. Additionally, if anything, such 
inter-hemispheric differences in neuropathology severity may have decreased our power to detect an association.

In conclusion, this unique dataset revealed differential MTL subregional atrophy patterns with different neurodegenerative pathologies. While the current study is limited by the use of the semi-quantitative scores of the different pathologies in the contralateral hemisphere and thickness measurements at a small number of anatomical locations, we aim to improve on this in future work as we are collecting serial immunohistochemistry of these four pathologies in the same hemisphere as the MRI, and matching it to structural MRI, in a subset of the participants $[54,68]$. This will allow for the creation of 3D neurodegenerative pathology maps which can be directly linked to local neurodegeneration. Moreover, as this dataset continues to grow, we will be able to further tease apart the effects of different neurodegenerative pathologies on MTL structure.

\section{Supplementary Information}

The online version contains supplementary material available at https://doi. org/10.1186/s40478-021-01225-3.

Additional file 1. Supplementary Methods and Results.

\section{Acknowledgements}

We gratefully acknowledge the tissue donors and their families. We also thank all the staff at Center for Neurodegenerative Research (University of Pennsylvania), especially John Robinson, and Human Neuroanatomy Lab (University of Castilla-La Mancha-UCLM) for performing the autopsies and making the tissue available for this project, as well as Sonia Herreros and personnel of the Department of Pathology, Albacete University Hospital.

\section{Authors' contributions}

LEMW, SR, LX, SRD, DAW and PAY contributed to study concept and design and analysis and interpretation of data. All authors contributed to the acquisition and processing of data. LEMW, SR and PAY contributed to drafting the manuscript. All authors performed drafting/revision of the manuscript for content.

\section{Funding}

Open access funding provided by Lund University. This work was supported in part by the National Institute of Health (Grants R01 EB017255, R01 AG056014, P30 AG010124, R01 AG054519, AG017586), a UCLM travel grant (to R.I.), a UCLM research grant to Human Neuroanatomy Laboratory and an Alzheimer's Association grant (AARF-19-615258) (to L.E.M.W).

\section{Availability of data and materials}

Anonymized data will be shared by request with any qualified investigator for purposes of validation and/or replication using our center's established methods for sharing data.

\section{Declarations}

\section{Ethics approval and consent to participate}

Human brain specimens were obtained in accordance with the University of Pennsylvania Institutional Review Board guidelines. Where possible, preconsent during life and, in all cases, next-of-kin consent at death was given.

\section{Consent for publication}

All authors have reviewed the contents of the manuscript being submitted, approved of its contents and validated the accuracy of the data and consented to publication.

\section{Competing interests}

A.W has received grant support from Merck, Biogen, and Eli Lilly/Avid and consultation fees from Neuronix and is on the DSMB for a clinical trial run by Functional Neuromodulation. L.X. received personal consultation fees from Galileo CDS, Inc. J.Q.T. may accrue revenue in the future on patents submitted by the University of Pennsylvania wherein he is co-Inventor and he received revenue from the sale of Avid to Eli Lily as co-inventor on imaging related patents submitted by the University of Pennsylvania.

\section{Author details}

'Department of Diagnostic Radiology, Lund University, Klinikgatan 13b, Lund, Sweden. ${ }^{2}$ Department of Radiology, University of Pennsylvania, Philadelphia, USA. ${ }^{3}$ Department of Pharmacology, University of North Carolina At Chapel Hill, Chapel Hill, USA. ${ }^{4}$ Department of Neurology, University of Pennsylvania, Philadelphia, USA. ${ }^{5}$ Center for Neurodegenerative Disease Research, University of Pennsylvania, Philadelphia, USA. ${ }^{6}$ Human Neuroanatomy Laboratory, Neuromax CSIC Associated Unit, University of Castilla La Mancha, Albacete, Spain.

Received: 18 June 2021 Accepted: 6 July 2021

Published online: 21 July 2021

\section{References}

1. Adler DH, Wisse LE, Ittyerah R, Pluta JB, Ding S, Xie L, Wang J, Kadivar S, Robinson JL, Schuck T (2018) Characterizing the human hippocampus in aging and Alzheimer's disease using a computational atlas derived from ex vivo MRl and histology. Proc Natl Acad Sci 115:4252-4257

2. Ardekani BA, Convit A, Bachman AH (2016) Analysis of the MIRIAD data shows sex differences in hippocampal atrophy progression. J Alzheimer Dis 50:847-857

3. Bejanin A, Murray ME, Martin P, Botha H, Tosakulwong N, Schwarz CG, Senjem ML, Chételat G, Kantarci K, Jack CR Jr (2019) Antemortem volume loss mirrors TDP-43 staging in older adults with non-frontotemporal lobar degeneration. Brain 142:3621-3635

4. Braak E, Braak H (1997) Alzheimer's disease: transiently developing dendritic changes in pyramidal cells of sector CA1 of the Ammon's horn. Acta Neuropathol 93:323-325

5. Braak H, Braak E (1991) Neuropathological stageing of Alzheimer-related changes. Acta Neuropathol 82:239-259

6. Braak H, Alafuzoff I, Arzberger T, Kretzschmar H, Del Tredici K (2006) Staging of Alzheimer disease-associated neurofibrillary pathology using paraffin sections and immunocytochemistry. Acta Neuropathol 112:389-404. https://doi.org/10.1007/s00401-006-0127-z

7. Brettschneider J, Del Tredici K, Irwin DJ, Grossman M, Robinson JL, Toledo JB, Fang L, Van Deerlin VM, Ludolph AC, Lee VM, Braak H, Trojanowski JQ (2014) Sequential distribution of pTDP-43 pathology in behavioral variant frontotemporal dementia (bvFTD). Acta Neuropathol 127:423-439. https://doi.org/10.1007/s00401-013-1238-y

8. Buciuc M, Wennberg AM, Weigand SD, Murray ME, Senjem ML, Spychalla AJ, Boeve BF, Knopman DS, Jack CR Jr, Kantarci K (2020) Effect modifiers of TDP-43 associated hippocampal atrophy rates in patients with Alzheimer's disease neuropathological changes. J Alzheimer Dis 74:1-13

9. Burton EJ, Mukaetova-Ladinska EB, Perry RH, Jaros E, Barber R, O'Brien JT (2012) Neuropathological correlates of volumetric MRI in autopsyconfirmed Lewy body dementia. Neurobiol Aging 33:1228-1236. https:// doi.org/10.1016/j.neurobiolaging.2010.12.015

10. Crary JF, Trojanowski JQ, Schneider JA, Abisambra JF, Abner EL, Alafuzoff I, Arnold SE, Attems J, Beach TG, Bigio EH, Cairns NJ, Dickson DW, Gearing M, Grinberg LT, Hof PR, Hyman BT, Jellinger K, Jicha GA, Kovacs GG, Knopman DS, Kofler J, Kukull WA, Mackenzie IR, Masliah E, McKee A, Montine TJ, Murray ME, Neltner JH, Santa-Maria I, Seeley WW, Serrano-Pozo A, Shelanski ML, Stein T, Takao M, Thal DR, Toledo JB, Troncoso JC, Vonsattel JP, White CL 3rd, Wisniewski T, Woltjer RL, Yamada M, Nelson PT (2014) Primary age-related tauopathy (PART): a common pathology associated 
with human aging. Acta Neuropathol 128:755-766. https://doi.org/10. 1007/s00401-014-1349-0

11. Dallaire-Théroux C, Callahan BL, Potvin O, Saikali S, Duchesne S (2017) Radiological-pathological correlation in Alzheimer's disease: systematic review of antemortem magnetic resonance imaging findings. J Alzheimer Dis 57:575-601

12. Das SR, Xie L, Wisse LE, Vergnet N, Ittyerah R, Cui S, Yushkevich PA, Wolk DA, Initiative ADN (2019) In vivo measures of tau burden are associated with atrophy in early Braak stage medial temporal lobe regions in amyloid-negative individuals. Alzheimers Dement 15:1286-1295

13. Das SR, Xie L, Wisse LE, Ittyerah R, Tustison NJ, Dickerson BC, Yushkevich PA, Wolk DA, Initiative ADN (2018) Longitudinal and cross-sectional structural magnetic resonance imaging correlates of AV-1451 uptake. Neurobiol Aging 66:49-58

14. Dawe RJ, Bennett DA, Schneider JA, Arfanakis K (2011) Neuropathologic correlates of hippocampal atrophy in the elderly: a clinical, pathologic, postmortem MRI study. PLOS ONE 6:e26286

15. de Flores R, Wisse LE, Das SR, Xie L, McMillan CT, Trojanowski JQ, Robinson $J$, Grossman M, Lee E, Irwin DJ (2020) Contribution of mixed pathology to medial temporal lobe atrophy in Alzheimer's disease. Alzheimers Dement 16:843-852

16. de Flores R, Berron D, Ding S, Ittyerah R, Pluta JB, Xie L, Adler DH, Robinson JL, Schuck T, Trojanowski JQ (2019) Characterization of hippocampal subfields using ex vivo MRI and histology data: Lessons for in vivo segmentation. Hippocampus 30:545-564

17. Duvernoy HM, Cattin E, Naidich T, Fatterpekar GM, Raybaud C, Risold PY, Sakvolini U, Scarabino T (2005) The human hippocampus. Springer, Berlin

18. Giannakopoulos P, Von Gunten A, Kövari E, Gold G, Herrmann FR, Hof PR, Bouras C (2007) Stereological analysis of neuropil threads in the hippocampal formation: relationships with Alzheimer's disease neuronal pathology and cognition. Neuropathol Appl Neurobiol 33:334-343

19. Giannakopoulos P, Herrmann FR, Bussière T, Bouras C, Kövari E, Perl DP, Morrison JH, Gold G, Hof PR (2003) Tangle and neuron numbers, but not amyloid load, predict cognitive status in Alzheimer's disease. Neurology 60:1495-1500

20. Giasson BI, Jakes R, Goedert M, Duda JE, Leight S, Trojanowski JQ, Lee VM (2000) A panel of epitope-specific antibodies detects protein domains distributed throughout human a-synuclein in lewy bodies of Parkinson's disease. J Neurosci Res 59:528-533

21. Gomez-Isla T, Hollister R, West H, Mui S, Growdon JH, Petersen RC, Parisi JE, Hyman BT (1997) Neuronal loss correlates with but exceeds neurofibrillary tangles in Alzheimer's disease. Ann Neurol 41:17-24. https://doi. org/10.1002/ana.410410106

22. Hodges JR, Patterson K, Oxbury S, Funnell E (1992) Semantic dementia. Progressive fluent aphasia with temporal lobe atrophy. Brain 115:1783-1806

23. Hyman BT, Phelps CH, Beach TG, Bigio EH, Cairns NJ, Carrillo MC, Dickson DW, Duyckaerts C, Frosch MP, Masliah E, Mirra SS, Nelson PT, Schneider JA, Thal DR, Thies B, Trojanowski JQ, Vinters HV, Montine TJ (2012) National Institute on Aging-Alzheimer's Association guidelines for the neuropathologic assessment of Alzheimer's disease. Alzheimers Dement 8:1-13. https://doi.org/10.1016/j.jalz.2011.10.007

24. Hyman BT, Phelps CH, Beach TG, Bigio EH, Cairns NJ, Carrillo MC, Dickson DW, Duyckaerts C, Frosch MP, Masliah E (2012) National Institute on Aging-Alzheimer's Association guidelines for the neuropathologic assessment of Alzheimer's disease. Alzheimers Dement 8:1-13

25. Jack CR Jr (2014) PART and SNAP. Acta Neuropathol 128:773-776. https:// doi.org/10.1007/s00401-014-1362-3

26. Jack CR Jr, Knopman DS, Weigand SD, Wiste HJ, Vemuri P, Lowe V, Kantarci K, Gunter JL, Senjem ML, Ivnik RJ, Roberts RO, Rocca WA, Boeve BF, Petersen RC (2012) An operational approach to National Institute on Aging-Alzheimer's Association criteria for preclinical Alzheimer disease. Ann Neurol 71:765-775. https://doi.org/10.1002/ana.22628

27. Jellinger KA (2018) Different patterns of hippocampal tau pathology in Alzheimer's disease and PART. Acta Neuropathol 136:811-813

28. Josephs KA, Murray ME, Tosakulwong N, Weigand SD, Serie AM, Perkerson RB, Matchett BJ, Jack CR, Knopman DS, Petersen RC (2019) Pathological, imaging and genetic characteristics support the existence of distinct TDP-43 types in non-FTLD brains. Acta Neuropathol 137:227-238

29. Josephs KA, Murray ME, Tosakulwong N, Whitwell JL, Knopman DS, Machulda MM, Weigand SD, Boeve BF, Kantarci K, Petrucelli L (2017)
Tau aggregation influences cognition and hippocampal atrophy in the absence of beta-amyloid: a clinico-imaging-pathological study of primary age-related tauopathy (PART). Acta Neuropathol 133:705-715

30. Josephs KA, Dickson DW, Tosakulwong N, Weigand SD, Murray ME, Petrucelli L, Liesinger AM, Senjem ML, Spychalla AJ, Knopman DS (2017) Rates of hippocampal atrophy and presence of post-mortem TDP-43 in patients with Alzheimer's disease: a longitudinal retrospective study. Lancet Neurol 16:917-924

31. Kapasi A, DeCarli C, Schneider JA (2017) Impact of multiple pathologies on the threshold for clinically overt dementia. Acta Neuropathol 134:171186. https://doi.org/10.1007/s00401-017-1717-7

32. Kerchner GA, Hess CP, Hammond-Rosenbluth $K E$, Xu D, Rabinovici GD, Kelley DA, Vigneron DB, Nelson SJ, Miller BL (2010) Hippocampal CA1 apical neuropil atrophy in mild Alzheimer disease visualized with 7-T MRI. Neurology 75:1381-1387

33. King A, Bodi I, Nolan M, Troakes C, Al-Sarraj S (2015) Assessment of the degree of asymmetry of pathological features in neurodegenerative diseases. What is the significance for brain banks? J Neural Transm 122:1499-1508

34. Kovacs GG (2015) Invited review: neuropathology of tauopathies: principles and practice. Neuropathol Appl Neurobiol 41:3-23

35. Lee EB, Skovronsky DM, Abtahian F, Doms RW, Lee VM (2002) Secretion and intracellular generation of truncated Abeta in BACE expressing human neurons. J Biol Chem 278:4458-4466

36. Liesinger AM, Graff-Radford NR, Duara R, Carter RE, Al-Shaikh FSH, Koga S, Hinkle KM, DiLello SK, Johnson MF, Aziz A (2018) Sex and age interact to determine clinicopathologic differences in Alzheimer's disease. Acta Neuropathol 136:873-885

37. Maass A, Lockhart SN, Harrison TM, Bell RK, Mellinger T, Swinnerton K, Baker SL, Rabinovici GD, Jagust WJ (2018) Entorhinal Tau pathology, episodic memory decline, and neurodegeneration in aging. J Neurosci 38:530-543. https://doi.org/10.1523/JNEUROSCI.2028-17.2017

38. Mackenzie IR, Neumann M (2020) Subcortical TDP-43 pathology patterns validate cortical FTLD-TDP subtypes and demonstrate unique aspects of C9orf72 mutation cases. Acta Neuropathol 139:83-98

39. Mackenzie IR, Neumann M, Bigio EH, Cairns NJ, Alafuzoff I, Kril J, Kovacs GG, Ghetti B, Halliday G, Holm IE (2010) Nomenclature and nosology for neuropathologic subtypes of frontotemporal lobar degeneration: an update. Acta Neuropathol 119:1-4

40. Makkinejad N, Schneider JA, Yu J, Leurgans SE, Kotrotsou A, Evia AM, Bennett DA, Arfanakis K (2019) Associations of amygdala volume and shape with transactive response DNA-binding protein 43 (TDP-43) pathology in a community cohort of older adults. Neurobiol Aging 77:104-111

41. Matej R, Tesar A, Rusina R (2019) Alzheimer's disease and other neurodegenerative dementias in comorbidity: a clinical and neuropathological overview. Clin Biochem 73:26-31

42. McKeith IG, Dickson DW, Lowe J, Emre M, O'brien JT, Feldman H, Cummings J, Duda JE, Lippa C, Perry EK (2005) Diagnosis and management of dementia with Lewy bodies: third report of the DLB Consortium. Neurology 65:1863-1872

43. Mirra SS, Heyman A, McKeel D, Sumi SM, Crain BJ, Brownlee LM, Vogel FS, Hughes JP, Van Belle G, Berg L (1991) The consortium to establish a registry for Alzheimer's disease (CERAD): Part II. Standardization of the neuropathologic assessment of Alzheimer's disease. Neurology 41:479

44. Montine TJ, Monsell SE, Beach TG, Bigio EH, Bu Y, Cairns NJ, Frosch M, Henriksen J, Kofler J, Kukull WA (2016) Multisite assessment of NIA-AA guidelines for the neuropathologic evaluation of Alzheimer's disease. Alzheimers Dement 12:164-169

45. Montine TJ, Phelps CH, Beach TG, Bigio EH, Cairns NJ, Dickson DW, Duyckaerts C, Frosch MP, Masliah E, Mirra SS (2012) National Institute on AgingAlzheimer's Association guidelines for the neuropathologic assessment of Alzheimer's disease: a practical approach. Acta Neuropathol 123:1-11

46. Nelson P, Dickson D, Trokanowski J, Jack C Jr, Boyle P, Arfanakis K, Rademakers R, Alafuzoff I, Attems J, Brayne C (2019) Limbic-predominant Age-related TDP-43 Encephalopathy (LATE): Consensus Working Group Report. Brain 142:1503-1527

47. Nelson PT, Dickson DW, Trojanowski JQ, Jack CR, Boyle PA, Arfanakis K, Rademakers R, Alafuzoff I, Attems J, Brayne C (2019) Limbic-predominant age-related TDP-43 encephalopathy (LATE): consensus working group report. Brain 142:1503-1527 
48. Neumann M, Kwong LK, Lee EB, Kremmer E, Flatley A, Xu Y, Forman MS, Troost D, Kretzschmar HA, Trojanowski JQ (2009) Phosphorylation of S409/410 of TDP-43 is a consistent feature in all sporadic and familial forms of TDP-43 proteinopathies. Acta Neuropathol 117:137-149

49. Ossenkoppele R, Lyoo CH, Jester-Broms J, Sudre $\mathrm{CH}$, Cho H, Ryu YH, Cho JY, Smith R, Strandberg O, Palmqvist S (2020) Assessment of Demographic, genetic, and imaging variables associated with brain resilience and cognitive resilience to pathological Tau in patients with Alzheimer disease. JAMA Neurol 77:632-642

50. Otvos L Jr, Feiner L, Lang E, Szendrei Gl, Goedert M, Lee VM (1994) Monoclonal antibody PHF-1 recognizes tau protein phosphorylated at serine residues 396 and 404. J Neurosci Res 39:669-673

51. Oveisgharan S, Arvanitakis Z, Yu L, Farfel J, Schneider JA, Bennett DA (2018) Sex differences in Alzheimer's disease and common neuropathologies of aging. Acta Neuropathol 136:887-900

52. Quintas-Neves M, Teylan MA, Besser L, Soares-Fernandes J, Mock CN, Kukull WA, Crary JF, Oliveira TG (2019) Magnetic resonance imaging brain atrophy assessment in primary age-related tauopathy (PART). Acta Neuropathol Commun 7:1-9

53. Ramanan VK, Castillo AM, Knopman DS, Graff-Radford J, Lowe VJ, Petersen RC, Jack CR, Mielke MM, Vemuri P (2019) Association of apolipoprotein E $\varepsilon 4$, educational level, and sex with tau deposition and tau-mediated metabolic dysfunction in older adults. JAMA Netw Open 2:e1913909

54. Ravikumar S, Wisse LE, Ittyerah R, Lim S, Lavery M, Xie L, Robinson JL, Schuck T, Grossman M, Lee EB, Tisdall MD, Prabhakaran K, Detre JA, Das SR, Mizsei G, Artacho-Perula E, Iniguez de Onzono Martin MM, ArroyoJimenez MM, Munoz M, Molina Romero FJ, Marcos Rabal MP, Irwin DJ, Trojanowski JQ, Wolk DA, Insausti R, Yushkevich PA (2020) Building an ex vivo atlas of the earliest brain regions affected by Alzheimer's Disease Pathology. In: 2020 IEEE 17th international symposium on biomedical imaging (ISBI), pp 113-117

55. Robinson JL, Lee EB, Xie SX, Rennert L, Suh E, Bredenberg C, Caswell C, Van Deerlin VM, Yan N, Yousef A (2018) Neurodegenerative disease concomitant proteinopathies are prevalent, age-related and APOE4associated. Brain 141:2181-2193

56. Schneider JA, Arvanitakis Z, Bang W, Bennett DA (2007) Mixed brain pathologies account for most dementia cases in community-dwelling older persons. Neurology 69:2197-2204. https://doi.org/10.1212/01.wnl. 0000271090.28148 .24

57. Stefanits H, Budka H, Kovacs GG (2012) Asymmetry of neurodegenerative disease-related pathologies: a cautionary note. Acta Neuropathol 123:449-452

58. Teipel SJ, Fritz H, Grothe MJ, Initiative ADN (2020) Neuropathologic features associated with basal forebrain atrophy in Alzheimer disease. Neurology 95:e1301-e1311

59. Thal DR, Rub U, Orantes M, Braak H (2002) Phases of A beta-deposition in the human brain and its relevance for the development of AD. Neurology 58:1791-1800

60. Toledo JB, Van Deerlin VM, Lee EB, Suh E, BaekY, Robinson JL, Xie SX, McBride J, Wood EM, Schuck T, Irwin DJ, Gross RG, Hurtig H, McCluskey L,
Elman L, Karlawish J, Schellenberg G, Chen-Plotkin A, Wolk D, Grossman M, Arnold SE, Shaw LM, Lee VM, Trojanowski JQ (2014) A platform for discovery: The University of Pennsylvania Integrated Neurodegenerative Disease Biobank. Alzheimers Dement 10:477-84.e1. https://doi.org/10. 1016/j.jalz.2013.06.003

61. von Gunten A, Kövari E, Bussière T, Rivara C, Gold G, Bouras C, Hof PR, Giannakopoulos P (2006) Cognitive impact of neuronal pathology in the entorhinal cortex and CA1 field in Alzheimer's disease. Neurobiol Aging 27:270-277

62. Wang L, Fagan AM, Shah AR, Beg MF, Csernansky JG, Morris JC, Holtzman DM (2012) Csf proteins predict longitudinal hippocampal degeneration in early stage dementia of the alzheimer type. Alzheimer Dis Assoc Disord 26:314

63. Wang L, Benzinger TL, Su Y, Christensen J, Friedrichsen K, Aldea P, McConathy J, Cairns NJ, Fagan AM, Morris JC (2016) Evaluation of tau imaging in staging Alzheimer disease and revealing interactions between $\beta$-amyloid and tauopathy. JAMA Neurol 73:1070-1077

64. Wennberg AM, Whitwell JL, Tosakulwong N, Weigand SD, Murray ME, Machulda MM, Petrucelli L, Mielke MM, Jack CR Jr, Knopman DS (2019) The influence of tau, amyloid, alpha-synuclein, TDP-43, and vascular pathology in clinically normal elderly individuals. Neurobiol Aging 77:26-36

65. Xie L, Das SR, Wisse LEM, Ittyerah R, Yushkevich PA, Wolk DA, Initiative ADN (2018) Early Tau burden correlates with higher rate of atrophy in transentorhinal cortex. J Alzheimers Dis 62:85-92. https://doi.org/10. 3233/JAD-170945

66. Yu L, Boyle PA, Dawe RJ, Bennett DA, Arfanakis K, Schneider JA (2020) Contribution of TDP and hippocampal sclerosis to hippocampal volume loss in older-old persons. Neurology 94:e142-e152

67. Yushkevich PA, Piven J, Hazlett HC, Smith RG, Ho S, Gee JC, Gerig G (2006) User-guided 3D active contour segmentation of anatomical structures: significantly improved efficiency and reliability. Neuroimage 31:1116-1128.

68. Yushkevich PA, Iñiguez de Onzoño Martin MM, Ittyerah R, Lim S, Lavery M Wang J, Hung LY, Vergnet N, Ravikumar S, Xie L, Dong M, de Flores R, Cui S, McCollum L, Ohm DT, Robinson JL, Schuck T, Grossman M, Tisdall MD, Prabhakaran K, Mizsei G, Das SR, Artacho-Perula E, Arroyo-Jimenez MM, Munoz Lopez M, Marcos Rabal MP, Molina Romero FJ, Lee EB, Trojanowski JQ, Wisse LEM, Wolk DA, Irwin DJ, Insausti R (2020) 3D mapping of tau neurofibrillary tangle pathology in the human medial temporal lobe. In: 2020 IEEE 17th international symposium on biomedical imaging (ISBI), pp $1312-1316$

\section{Publisher's Note}

Springer Nature remains neutral with regard to jurisdictional claims in published maps and institutional affiliations.

Ready to submit your research? Choose BMC and benefit from

- fast, convenient online submission

- thorough peer review by experienced researchers in your field

- rapid publication on acceptance

- support for research data, including large and complex data types

- gold Open Access which fosters wider collaboration and increased citations

- maximum visibility for your research: over 100M website views per year

At BMC, research is always in progress.

Learn more biomedcentral.com/submissions 